OPEN ACCESS

Edited by: Mats Bemark,

University of Gothenburg, Sweden

Reviewed by: Johan K. Sandberg, Karolinska Institutet, Sweden Bradley D. Jones,

University of lowa, USA

*Correspondence: Rosângela Salerno-Goncalves rsalerno@medicine.umaryland.edu

Specialty section:

This article was submitted to Mucosal Immunity, a section of the journal

Frontiers in Immunology

Received: 05 January 2017 Accepted: 21 March 2017

Published: 06 April 2017

Citation:

Salerno-Goncalves R, Luo D, Fresnay S, Magder L, Darton TC,

Jones $C$, Waddington CS, Blohmke CJ, Angus B, Levine MM,

Pollard AJ and Sztein MB (2017)

Challenge of Humans with Wild-type Salmonella enterica Serovar Typhi Elicits Changes in the Activation and Homing Characteristics of Mucosal-Associated Invariant T Cells. Front. Immunol. 8:398. doi: 10.3389/fimmu.2017.00398

\section{Challenge of Humans with Wild-type Salmonella enterica Serovar Typhi Elicits Changes in the Activation and Homing Characteristics of Mucosal- Associated Invariant T Cells}

\author{
Rosângela Salerno-Goncalves ${ }^{1 *}$, David Luo ${ }^{1}$, Stephanie Fresnay', Laurence Magder', \\ Thomas C. Darton ${ }^{3}$, Claire Jones ${ }^{3}$, Claire S. Waddington ${ }^{3}$, Christoph J. Blohmke ${ }^{3}$, Brian \\ Angus $^{3}$, Myron M. Levine', Andrew J. Pollard ${ }^{3}$ and Marcelo B. Sztein ${ }^{1}$
}

\footnotetext{
${ }^{1}$ Center for Vaccine Development, University of Maryland School of Medicine, Baltimore, MD, USA, ${ }^{2}$ Department of Epidemiology and Public Health, University of Maryland School of Medicine, Baltimore, MD, USA, ${ }^{3}$ Oxford Vaccine Group, Department of Paediatrics, University of Oxford, Oxford, UK
}

Gastrointestinal infections by Salmonella enterica serovar Typhi (S. Typhi) are rare in industrialized countries. However, they remain a major public health problem in the developing world with an estimated 26.9 million new cases annually and significant mortality when untreated. Recently, we provided the first direct evidence that CD8 ${ }^{+}$ MAIT cells are activated and have the potential to kill cells exposed to S. Typhi, and that these responses are dependent on bacterial load. However, MAIT cell kinetics and function during bacterial infections in humans remain largely unknown. In this study, we characterize the human CD8 ${ }^{+}$MAIT cell immune response to S. Typhi infection in subjects participating in a challenge clinical trial who received a low- or high dose of wild-type S. Typhi. We define the kinetics of $\mathrm{CD} 8^{+}$MAIT cells as well as their levels of activation, proliferation, exhaustion/apoptosis, and homing potential. Regardless of the dose, in volunteers resistant to infection (NoTD), the levels of CD8+ MAIT cells after $S$. Typhi challenge fluctuated around their baseline values (day 0). In contrast, volunteers susceptible to the development of typhoid disease (TD) exhibited a sharp decline in circulating MAIT cells during the development of typhoid fever. Interestingly, MAIT cells from low-dose TD volunteers had higher levels of CD38 coexpressing CCR9, CCR6, and Ki67 during the development of typhoid fever than high-dose TD volunteers. No substantial perturbations on the levels of these markers were observed in NoTD volunteers irrespective of the dose. In sum, we describe, for the first time, that exposure to an enteric bacterium, in this case $S$. Typhi, results in changes in MAIT cell activation, proliferation, and homing characteristics, suggesting that MAIT cells are an important component of the human host response to bacterial infection.

Keywords: MAIT cells, T cells, human, gut, bacteria, Salmonella 


\section{INTRODUCTION}

MAIT cells are an "innate" like population of T cells that display a TCR V $\alpha 7.2^{+} \mathrm{CD} 161^{+}$phenotype and are restricted by the nonclassical MHC-related molecule 1 (MR1) (1-3). While thymic MAIT cells have the ability to respond to bacterial stimulation by upregulating activation (CD127) and proliferation (Ki67) markers, their cell surface phenotype is similar to that of naive $\mathrm{T}$ cells $(4,5)$. After birth, MAIT cells acquire a memory phenotype and expand dramatically in the mucosa and periphery. MAIT cells are few and naive in cord blood (6) but constitute up to $10 \%$ of human blood $\mathrm{T}$ cells in adults (7), making their biology and behavior relatively easy to study in ex vivo assays. Human MAIT cells also express molecules such as CD26, CD45RO, and transcription factors ROR $\gamma$ t and ZBTB16, which are involved in their function (7-10). Moreover, they express on their cell surface high levels of cytokine receptors for IL-18, IL-12, and IL-23 $(6,7)$ and can secrete TNF- $\alpha$, IFN- $\gamma$, IL-17, granzyme $a / b$, and perforin $(3,7,11$, 12), the latter reinforcing their cytotoxic capability. MAIT cells can also harbor strong immune responses to various bacteria including gut commensals and pathogens from the Enterobacteriaceae family (e.g., Salmonella) (12). Recently, we provided the first direct evidence that $\mathrm{CD}^{+}$MAIT cells are activated, able to secrete cytokines and exhibit cytotoxic properties against B cells exposed to gut commensals and pathogens such as Salmonella enterica serovar Typhi (S. Typhi) (12). These responses were MR1 restricted and involved the endocytic pathway. Moreover, the quality of these responses (i.e., cytokine profiles) was dependent on bacterial load, but not on the level of expression of MR1 or bacterial antigen on B cell surfaces (12). Thus, the evaluation of the influence of the bacterial load in $\mathrm{CD}^{+}$MAIT cell kinetics may provide further insight of the $\mathrm{CD} 8^{+}$MAIT cell role during bacterial infection.

Challenge studies in which healthy adult volunteers are intentionally infected with wild-type pathogens to test drugs and vaccines are a particularly relevant model for Salmonella infection. In the 1950s and 1970s, Dr. Theodore E. Woodward and Dr. Myron M. Levine of the University of Maryland in Baltimore conducted challenge studies with $S$. Typhi that led to the use of chloramphenicol in the treatment of patients with typhoid fever (13) and helped speed up the development of the Ty21a typhoid vaccine (14), the only oral live-attenuated vaccine licensed in

A

Gating strategy for MAIT cells

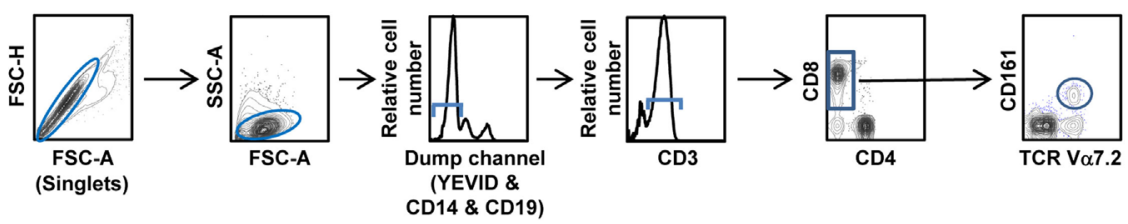

Low-Dose

High-Dose
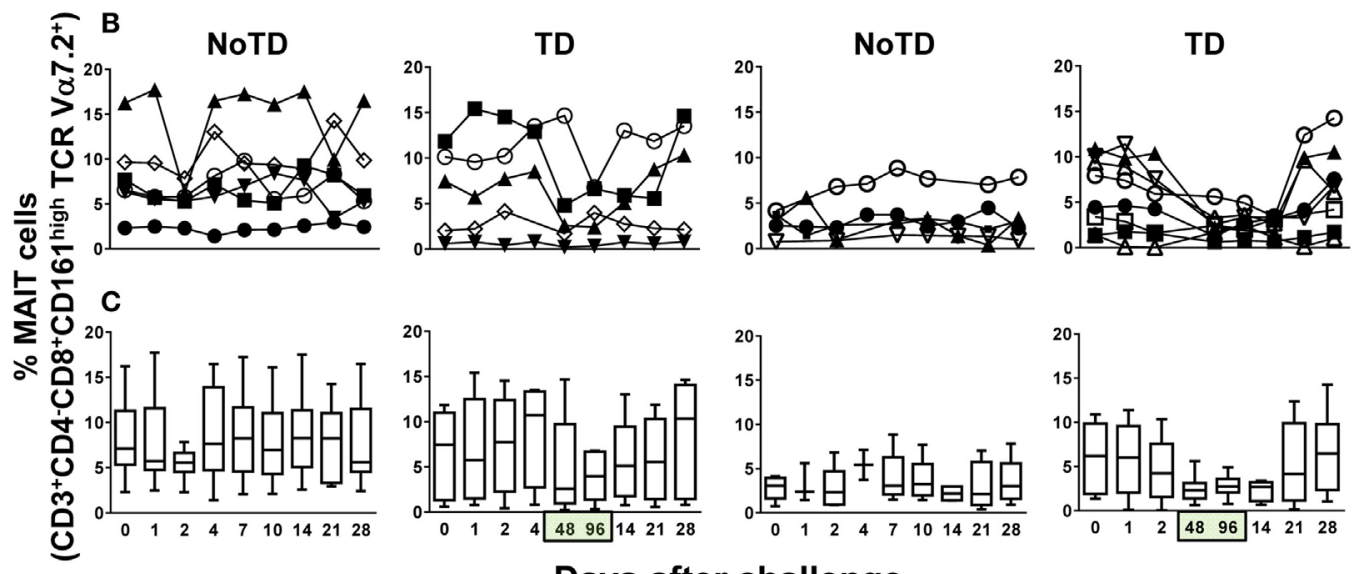

Days after challenge

FIGURE 1 | Kinetics of MAIT cells over a 28-day post-challenge follow-up period. Ex vivo peripheral blood mononuclear cells were stained with YEVID, followed by surface staining with monoclonal antibodies to CD3, CD4, CD8, CD14, CD19, CD161, and TCR 7.2 and analyzed by multichromatic flow cytometry. For the analysis, following the elimination of doublets and other debris, the cells were gated on lymphocytes, and then a "dump" channel was used to eliminate dead cells (YEVID+) as well as macrophages (CD14+), and B cells (CD19+) from the analyses. This was followed by additional gating on CD3, CD4, and CD8, as well as CD161 vs. TCR $\alpha 7.2$ to analyze MAIT cells. (A) A representative gating strategy for MAIT cells. (B) Individual volunteers and (C) combined data of MAIT cell kinetics. Bar graphs extend from the 25th to 75th percentiles, and the line in the middle represents the median of the pooled data from all the volunteers. The whiskers delineate the smallest to the largest value. Numbers in the " $X$ " axis represent days after the challenge, except for the numbers inside of the green box that represent 48 and $96 \mathrm{~h}$ after diagnosis of typhoid disease. NoTD, volunteers who did not develop typhoid disease; TD, volunteers who developed typhoid disease. 


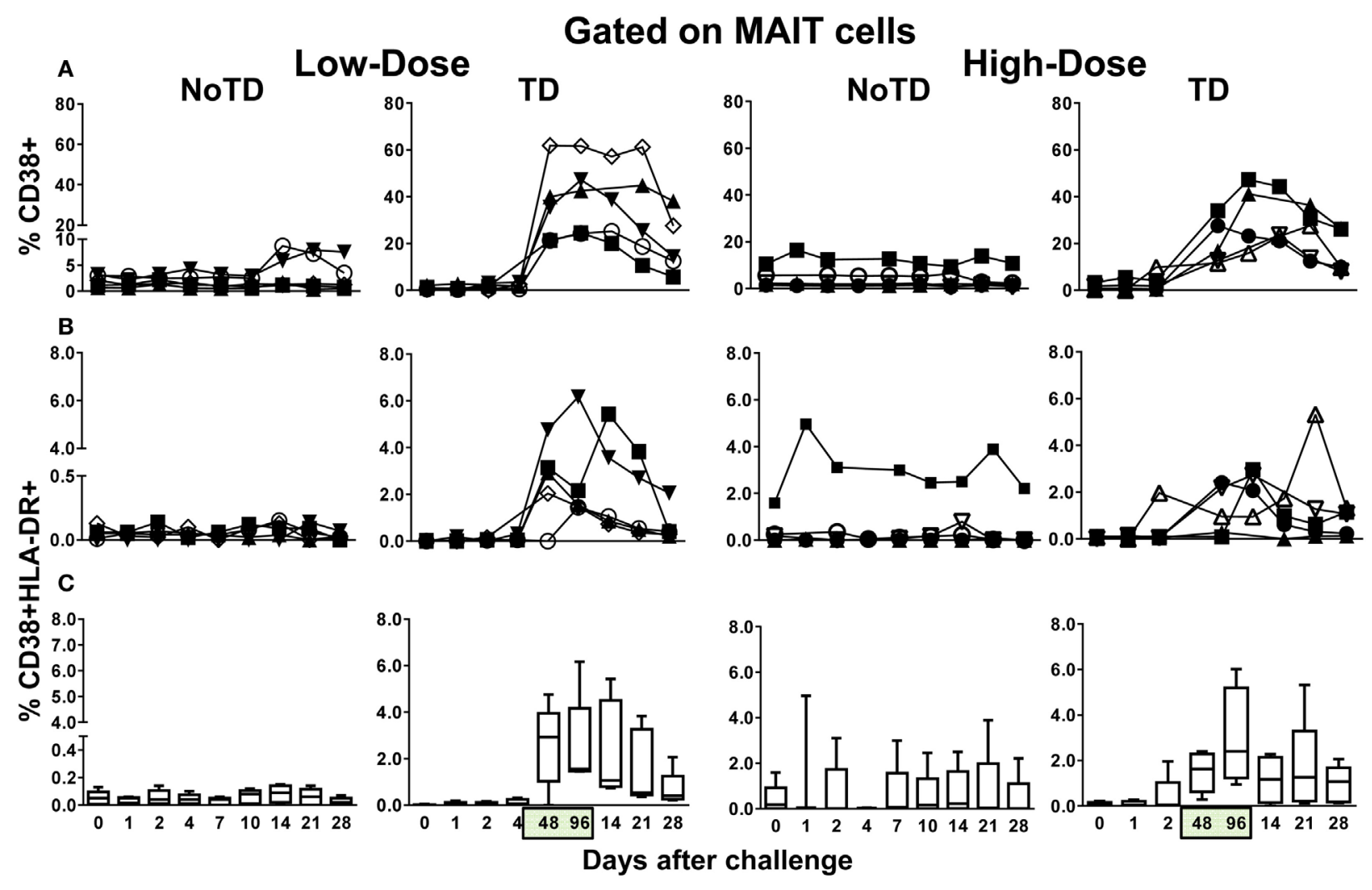

D

Gated on MAIT cells

Low Dose
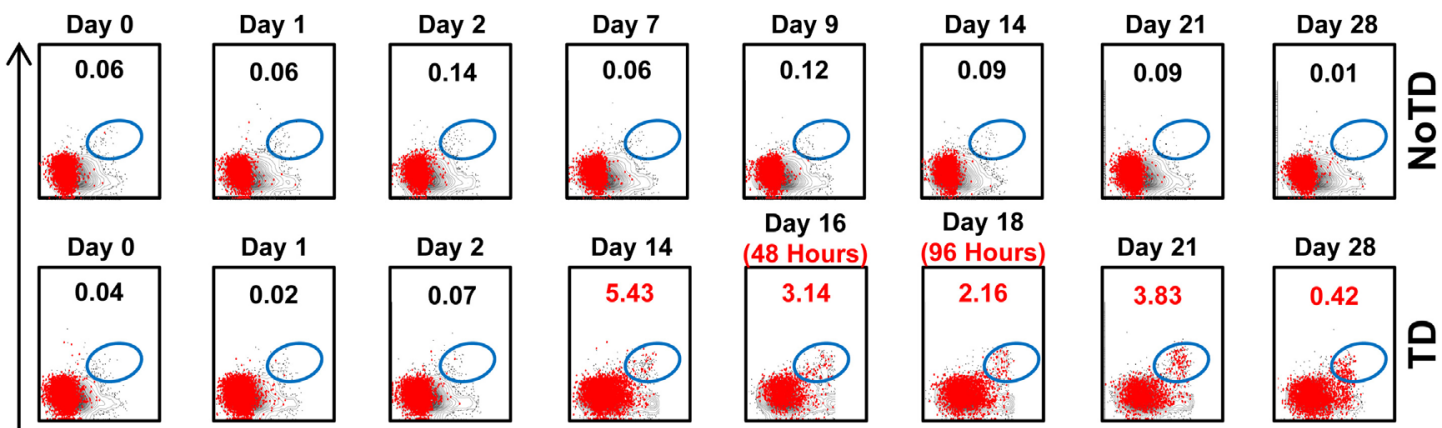

\section{High Dose}
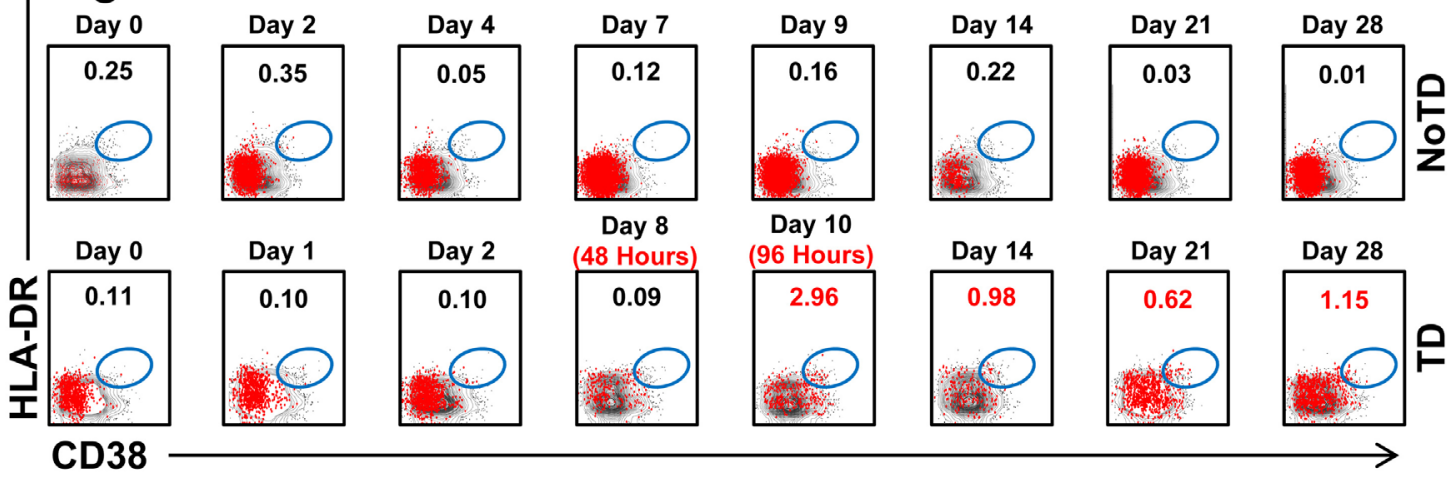

Day 10
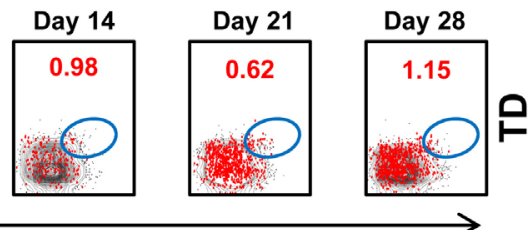

$\mathrm{CD}^{+}{ }^{+} \mathrm{CD} 4{ }^{-} \mathrm{CD} 8^{+} \mathrm{CD} 161^{+} \mathrm{TCR}$ V $\alpha 7.2^{+}$MAIT cells

$\mathrm{CD}^{+}{ }^{+} \mathrm{CD} 4-\mathrm{CD} 8^{+} \mathrm{T}$ cells 


\section{FIGURE 2 | Continued}

MAIT cell activation following Salmonella enterica serovar Typhi challenge. Ex vivo peripheral blood mononuclear cells were analyzed as described in Figure 1. Expression of CD38 and HLA-DR was evaluated to identify activated MAIT cells. Activated MAIT cells in individual volunteers expressing (A) CD38 or coexpressing (B) CD38 and HLA-DR surface markers. (C) Combined data of the activated MAIT cells coexpressing CD38 and HLA-DR surface markers in all volunteers. (D) Representative data of MAIT cells coexpressing CD38 and HLA-DR surface markers within the CD3+CD4-CD8+ T cell population. Bar graphs extend from the 25th to 75th percentiles, and the line in the middle represents the median of the pooled data from the five different subjects. The whiskers delineate the smallest to the largest value. Numbers in the " $X$ " axis represent days after the challenge, except for the numbers inside of the green box that represent 48 and $96 \mathrm{~h}$ after diagnosis of typhoid disease. NoTD, volunteers who did not develop typhoid disease; TD, volunteers who developed typhoid disease.

the US (15). More recently, Dr. Pollard's group [Oxford Vaccine Group (OVG), UK] has shown that by using smaller inoculums of virulent $S$. Typhi $\left[\sim 10^{3}\right.$ or $\sim 10^{4}$ colony-forming units (CFU)] administered following ingestion of a bicarbonate solution, the challenge can be performed safely, with attack rates in excess of $50 \%$ (14). In a previous study (12), we evaluated the impact of bacterial load on the restimulation of a "pre-formed pool" of $\mathrm{CD}^{+}$MAIT cells. The present studies extend these observations by studying $\mathrm{CD} 8^{+}$MAIT cell expansion and/or burst size in vivo after exposure to different $S$. Typhi bacterial loads. Using cells from volunteers participating in an Oxford challenge study who received a low- or high dose of wild-type $S$. Typhi, we investigated the ex vivo kinetics of $\mathrm{CD}^{+}$MAIT cell responses for up to 28 days after the challenge. We also defined $\mathrm{CD}^{+} \mathrm{MAIT}$ cell proliferation (Ki67), activation (CD38 and HLA-DR), exhaustion/apoptosis (CD57, caspase-3), and homing (CCR9 and CCR6) markers in mediating these responses. Regardless of the dose, in volunteers resistant to the infection (NoTD), the levels of $\mathrm{CD}^{+}$MAIT cells after $S$. Typhi challenge fluctuated around their baseline values (day 0 ). In contrast, in volunteers susceptible to the development of typhoid disease (TD) we observed a sharp decline in circulating $\mathrm{CD}^{+}$MAIT cells during the development of typhoid fever. Interestingly, we found that TD volunteers exposed to low doses of wild-type $S$. Typhi $\left(10^{3} \mathrm{CFU}\right)$ had higher levels of $\mathrm{CD}^{+}$ MAIT cells coexpressing CD38 and either CCR9, CCR6, or Ki67 during the development of typhoid fever than TD volunteers receiving a high dose of $S$. Typhi $\left(10^{4} \mathrm{CFU}\right)$.

In sum, we describe, for the first time, that exposure to an enteric bacterium, in this case $S$. Typhi, results in changes in MAIT cell activation, proliferation, and homing characteristics. These results suggest that MAIT cells are an important component of the human host response to bacterial infection.

\section{MATERIALS AND METHODS}

\section{Subjects}

Healthy volunteers, between 18 and 60 years old, were screened for good health by medical history, physical examination, and normal laboratory tests, including blood counts. Individuals who previously received typhoid vaccination or have a residence for $>6$ months in typhoid-endemic areas were not eligible to participate in the study. A 2 -week course of antibiotic treatment was initiated if typhoid diagnosis occurred (temperature $\geq 38^{\circ} \mathrm{C}$ sustained $\geq 12 \mathrm{~h}$ or bacteremia) or at day 14 post-challenge for the volunteers who did not develop typhoid fever (14). Twenty volunteers, 10 volunteers who received high $\left(10^{4} \mathrm{CFU}\right)$ and 10 volunteers who received low $\left(10^{3} \mathrm{CFU}\right)$ dose of the $S$. Typhi inoculum, and whose peripheral blood mononuclear cells (PBMC) were available were selected for the studies described in this manuscript (Table S1 in Supplementary Material). Highand low-dose inoculum groups were composed of volunteers who developed TD or not (Table S1 in Supplementary Material). Time points selected for the studies described in this manuscript included before and up to 28 days after the challenge. PBMC isolated from these volunteers were studied ex vivo without any in vitro stimulation.

\section{Antibodies and Cell Culture Media}

Cells were surface stained with anti-human monoclonal antibodies (mAbs) to CD3 (clone OKT3), CD14 (clone M5E2), CD19 (clone HIB19), CD161 (clone HP-3G10), TCR Va7.2 (clone 3C10) (Biolegend, San Diego, CA, USA), CD4 (clone L200), CD8 (clone SK1), activated caspase-3 (clone C92-605), CCR6 (clone 11A9), HLA-DR (clone G46-6), Ki67 (clone B56) (BD Pharmingen, San Diego, CA, USA), CCR9 (clone 112509) (R\&D, Minneapolis, MN, USA), CD38 (clone LS198.4.3) (BeckmanCoulter, Miami, FL, USA), and CD57 [clone TB01 (TB01); eBioscience, San Diego, CA, USA]. Antibodies conjugated to the following fluorochromes were used in these studies: fluorescein isothiocyanate (FITC), phycoerythrin (PE), peridinin chlorophyll protein (PerCP)-Cy5.5, PE-Cy7, energy coupled dye or PE-Texasred conjugate (ECD), violet (V) 450 (e.g., similar to Pacific blue), brilliant violet (BV) 570, BV605, BV650, quantum dot (QD) 800, Alexa 647, allophycocyanin (APC)-Alexa 700 and APC-H7.

Culture medium consisted of RPMI 1640 (Gibco, Grand Island, NY, USA) supplemented with $100 \mathrm{U} / \mathrm{ml}$ penicillin, $100 \mu \mathrm{g} /$ $\mathrm{ml}$ streptomycin, $50 \mu \mathrm{g} / \mathrm{ml}$ gentamicin, $2 \mathrm{mM}$ L-glutamine, $2.5 \mathrm{mM}$ sodium pyruvate, $10 \mathrm{mM}$ HEPES buffer, and $10 \%$ heatinactivated fetal bovine serum (R10).

\section{Surface and Intracellular Staining}

Ex vivo PBMC were used for this experiment. Briefly, after overnight $(16-18 \mathrm{~h})$ resting at $37^{\circ} \mathrm{C}, 5 \% \mathrm{CO}_{2}, \mathrm{PBMC}$ were harvested, stained with a dead-cell discriminator, yellow fluorescent viability dye (YEVID, Invitrogen, Carlsbad, CA, USA) (16), followed by surface staining with $\mathrm{mAbs}$ against caspase-3, CCR6, CCR9, CD3, CD4, CD8, CD14, CD19, CD38, CD57, CD161, HLA-DR, and TCR $\alpha 7.2$ surface antigens and fixation and permeabilization with Fix \& Perm cell buffers (Invitrogen, Carlsbad, CA, USA) $(12,16)$. Cells were then stained intracellularly for Ki67. Finally, cells were resuspended in fixation buffer ( $1 \%$ formaldehyde) and analyzed as soon as possible by flow cytometry on an LSR-II instrument (BD Biosciences). Data were analyzed with WinList v6.0 (Verity Software House, Topsham, ME, USA). Lymphocytes were gated 


\section{Gated on MAIT cells}

\section{Low-Dose}

A
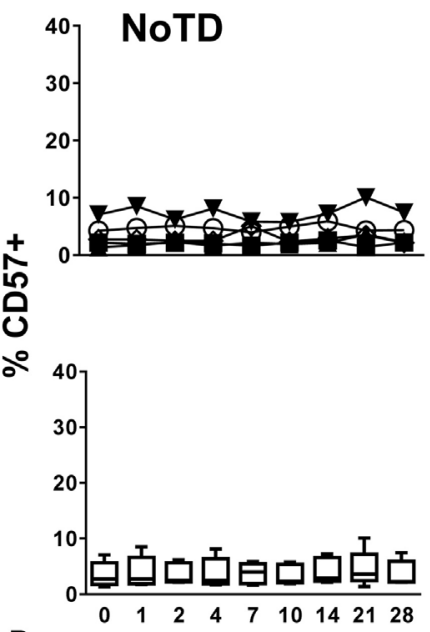

B
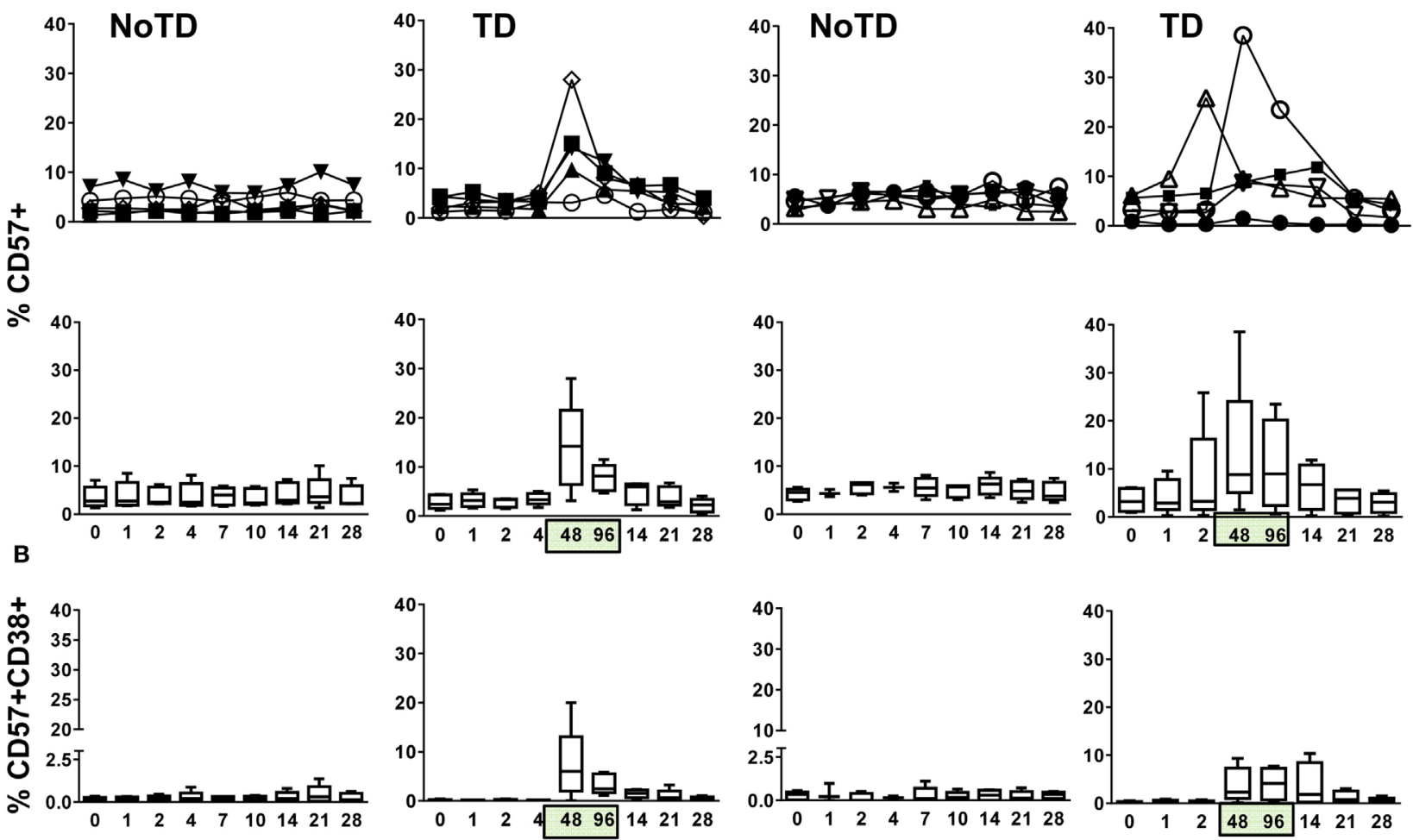

C
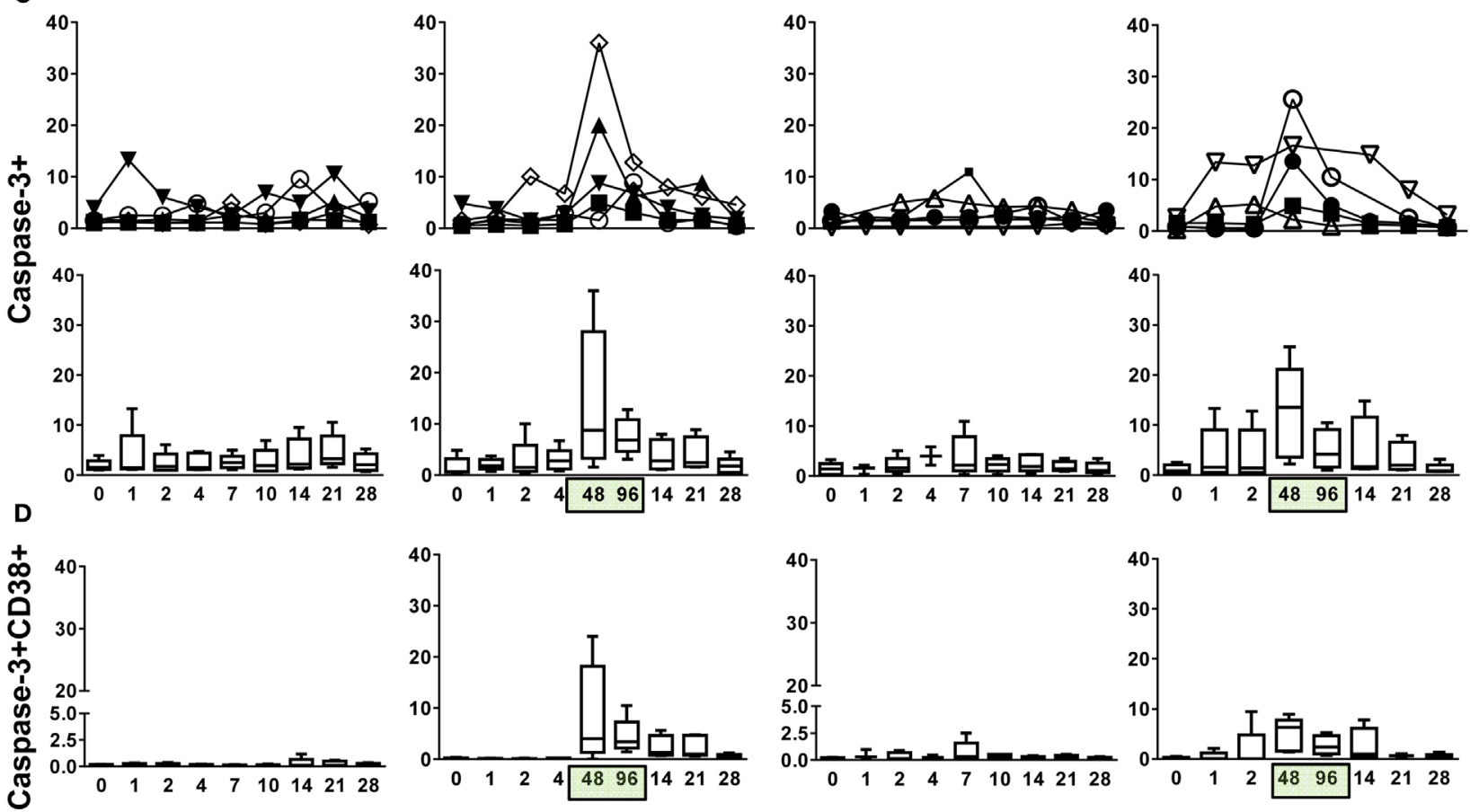

\section{Days after challenge}




\section{FIGURE 3 | Continued}

Identification of exhausted and apoptotic MAIT cells following Salmonella enterica serovar Typhi challenge. Ex vivo peripheral blood mononuclear cells were analyzed as described in Figure 1. Expression of CD57 and caspase-3 were performed to identify exhausted and apoptotic MAIT cells, respectively. Combined data of MAIT cells expressing (A) CD57 or coexpressing (B) CD57 and CD38 surface markers. Combined data of MAIT cells expressing (C) caspase-3 or coexpressing (D) caspase-3 and CD38 surface markers. Bar graphs extend from the 25th to 75th percentiles, and the line in the middle represents the median of the pooled data from the five different subjects. The whiskers delineate the smallest to the largest value. Numbers in the " $X$ " axis represent days after the challenge, except for the numbers inside of the green box that represent 48 and $96 \mathrm{~h}$ after diagnosis of typhoid disease. NoTD, volunteers who did not develop typhoid disease; TD, volunteers who developed typhoid disease.

based on their scatter characteristics. Single lymphocytes were gated based on forward scatter height vs. forward scatter area. A "dump" channel was used to eliminate dead cells $\left(\mathrm{YEVID}^{+}\right)$ as well as macrophages/monocytes $\left(\mathrm{CD} 14^{+}\right)$and $\mathrm{B}$ lymphocytes $\left(\mathrm{CD} 19^{+}\right)$from analysis. This was followed by additional gating on CD3, CD8, CD161, and TCR V 27.2 to identify MAIT cells. During sample acquisition, routinely 300,000-500,000 events were collected in the forward and side scatter lymphocyte gate. This large number of gated MAIT cell events was essential to ensure that a sufficient number of positive cells for defined subsets would be collected for each tube analyzed.

\section{Statistical Analysis}

All statistical tests were performed using SAS 9.3 (Cary, NC, USA). Observations were grouped by day following challenge in the following periods: pre-challenge, days 1-4, days 7-9 or within $48-96 \mathrm{~h}$ of disease onset, and days 14-28. Volunteers generally contributed more than one observation to each time period. To compare mean values by time period and group, while accounting for correlation between multiple measures from the same volunteer at the same time period and across time periods, we used mixed effects models. These models, which include a random effect for the subject, were fit by restricted maximum likelihood. Correlations used the Pearson product-moment tests. $P$ values $<0.05$ were considered significant.

\section{RESULTS}

\section{Kinetics of MAIT Cells over a 28-Day Post-Challenge Follow-Up}

Because of the potential importance of $\mathrm{CD}^{+}$MAIT cells (henceforth called MAIT cells) in resistance to bacterial infection, in particular to Salmonella infection (12), we investigated their kinetics in subjects participating in a dose-escalation challenge clinical trial conducted by Dr. Pollard's group (Oxford Vaccine Group) (14). This study was performed using the antibiotic susceptible, virulent wild-type $S$. Typhi Quailes strain, which was first isolated in 1958 from the gallbladder of a known chronic carrier $(14,15$, 17). Two separate cohorts were recruited, with one cohort receiving high $\left(\sim 10^{4} \mathrm{CFU}\right)$ and another one receiving low $\left(\sim 10^{3} \mathrm{CFU}\right)$ dose of the $S$. Typhi inoculum. The characteristics of the volunteers used for the studies presented in this manuscript are included in the Table S1 in Supplementary Material. Based on our previous data showing that $S$. Typhi-specific $C D 8^{+} \mathrm{T}$ cell responses can be detected as early as 4 days after typhoid fever immunization (18, 19) or challenge with $S$. Typhi (20), we hypothesized that changes in MAIT cell kinetics might be seen at even earlier time points (e.g., days 1 and 2) after the challenge. Innate-like T cells such as MAIT cells are known to respond very rapidly $(<2 \mathrm{~h})$ after activation and within the first few days postinfection $(5,21)$. To test this hypothesis, ex vivo PBMC collected before and up to 28 days after the challenge (including days 1 and 2) were surface stained with mAbs to CD3, CD4, CD8, CD14, CD19, CD161, and TCR $\alpha$ 7.2 and analyzed by multichromatic flow cytometry. MAIT cells were defined as $\mathrm{CD}^{+} \mathrm{CD}^{-}{ }^{-} \mathrm{CD} 8^{+} \mathrm{TCR} \mathrm{V} \alpha 7.2^{+} \mathrm{CD} 161^{+}$cells (Figure 1A; Figure S1 in Supplementary Material). We found that regardless of the dose, in volunteers resistant to the infection (NoTD), the levels of MAIT cells after $S$. Typhi challenge fluctuated around their baseline values (day 0) (Figures 1B,C; Figures S2A and S3A in Supplementary Material). In contrast, in volunteers susceptible to the development of TD, we observed a sharp decline of MAIT cells 48 and $96 \mathrm{~h}$ after diagnosis, a time frame used to capture the events occurring immediately after the development of typhoid fever (Figures 1B,C; Figures S2A, $\mathrm{S} 3 \mathrm{~A}$, and S4A in Supplementary Material). These results indicate that TD affects the kinetics of circulating MAIT cells. Of note, it is important to observe that the time to clinical diagnosis of typhoid fever was variable among the TD volunteers (i.e., ranging 6-13 and 6-10 days after the challenge for low- and high-dose volunteers, respectively) (Table S1 in Supplementary Material). For this reason, to align the time frames in which the various volunteers developed TD, we expressed the data as 48 and $96 \mathrm{~h}$ after typhoid diagnosis.

\section{MAIT Cell Activation following Challenge with Wild-type S. Typhi}

To further investigate the association between decreases in the numbers of circulating MAIT cells and their functionality, we next measured the expression of CD38 and HLA-DR activation markers. CD38 and HLA-DR are well-known activation molecules expressed on the cell surface of activated $\mathrm{T}$ cells during the acute phase of bacterial and viral infections in humans (22-24). Regardless of the dose, we found that challenge elicited increased levels of activated MAIT cells (either $\mathrm{CD} 38^{+}$single positive or CD $38^{+}$HLA-DR ${ }^{+}$double positive) in TD volunteers, a phenomenon that was associated with the time of TD (48 and $96 \mathrm{~h}$ after diagnosis of typhoid fever) (Figures 2A-D). Interestingly, the magnitude of the activation of $\mathrm{CD}^{+} 8^{+}$single positive, but not CD $38^{+}$HLA-DR ${ }^{+}$double positive MAIT cells was significantly higher in volunteers in the low-dose cohort than in those in the high-dose group (Figure S4B in Supplementary Material). Only minimal perturbations on levels of CD38 or HLA-DRexpressing MAIT cells were observed in NoTD volunteers (Figures 2A-D; Figures S2B and S3B in Supplementary Material). 
Gated on MAIT cells

Low-Dose

A
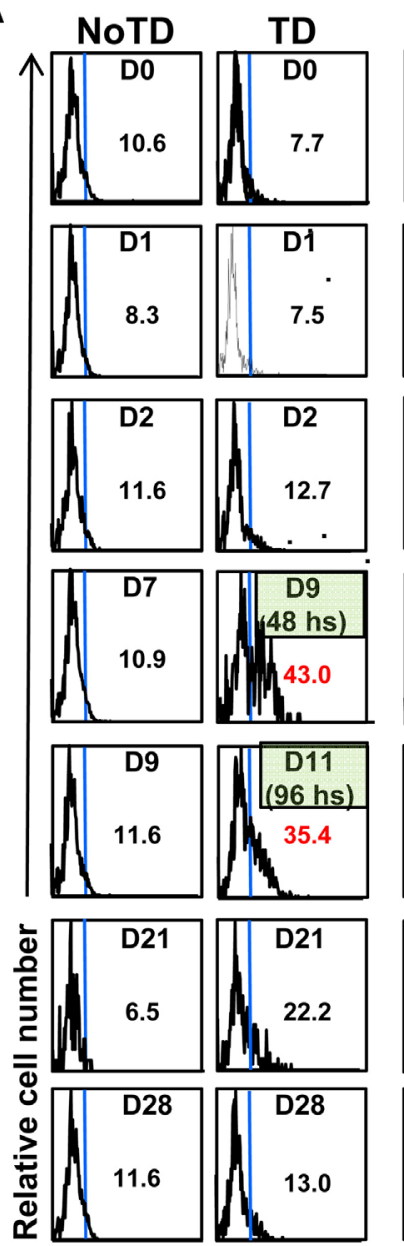

Ki67
High-Dose
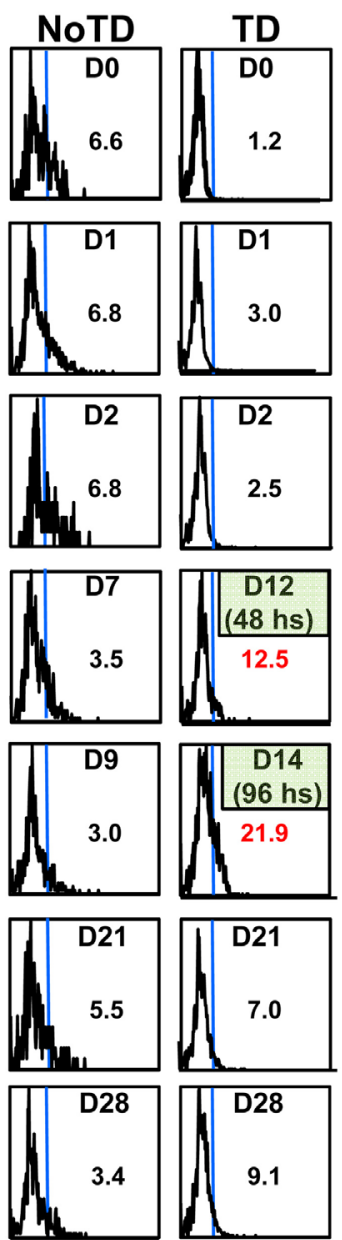

\section{Gated on MAIT cells}

Low-Dose

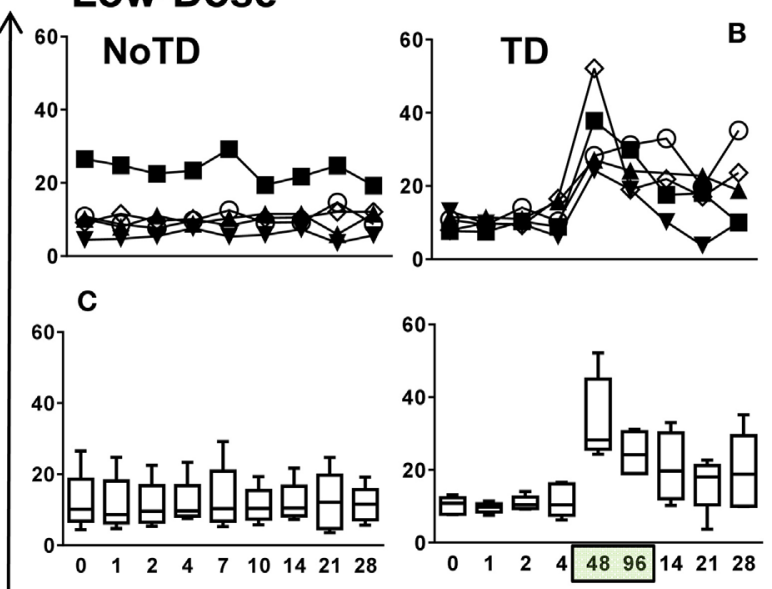

High-Dose

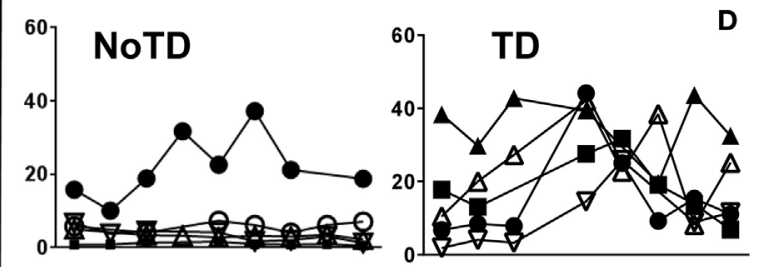

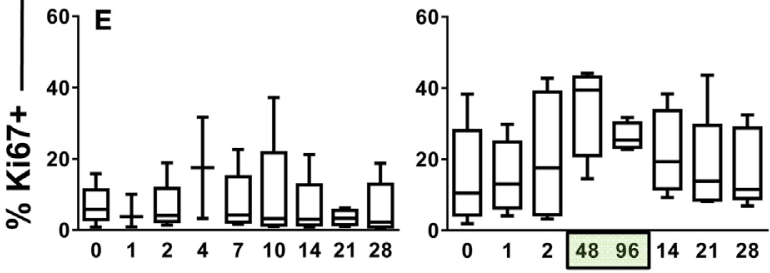

Days after challenge

\section{Gated on Ki67+ MAIT cells}
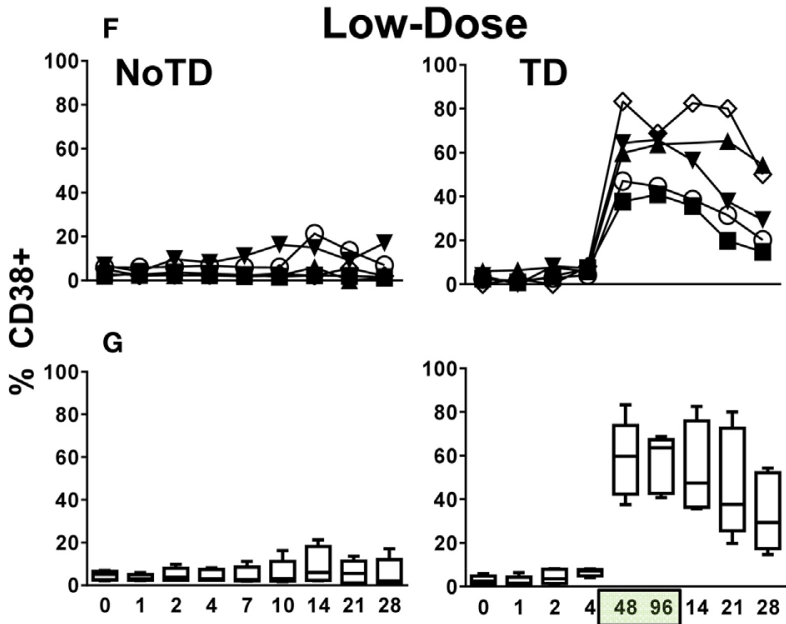

High-Dose
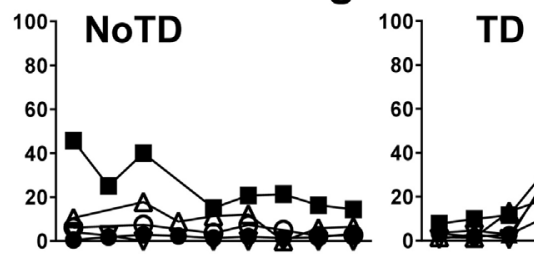

D
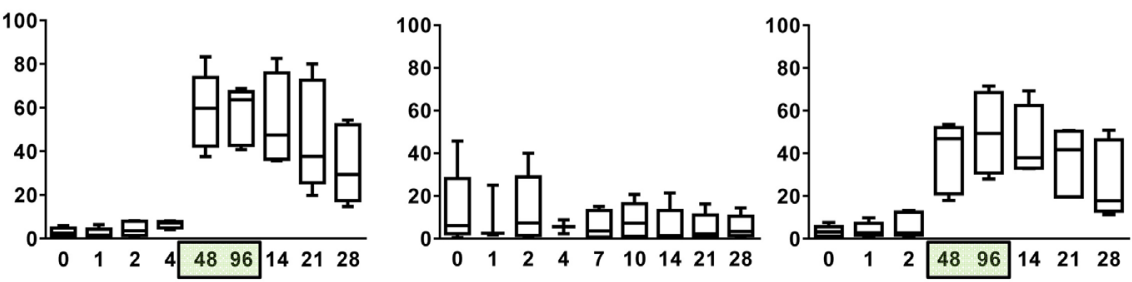

Days after challenge 
FIGURE 4 | Continued

MAIT cell proliferation following Salmonella enterica serovar Typhi challenge. Ex vivo peripheral blood mononuclear cells were analyzed as described in Figure 1. Ki67 expression was used to identify proliferating MAIT cells. (A) Representative data of intracellular expression of Ki67 ${ }^{+}$MAIT cells over a 28 -day post-challenge follow-up period in NoTD and typhoid disease (TD) volunteers who received a low- or high-dose challenge. (B) Individual and (C) combined data of proliferating MAIT cells from volunteers receiving a low-dose challenge. (D) Individual and (E) combined data of proliferating MAIT cells from volunteers receiving a high-dose challenge. (F) Individual and (G) combined data of CD38-positive cells gated on proliferating (Ki67 ${ }^{+}$) MAIT cells. Bar graphs extend from the 25th to 75 th percentiles, and the line in the middle represents the median of the pooled data from the five different subjects. The whiskers delineate the smallest to the largest value. Numbers in the " $X$ " axis represent days after the challenge, except for the numbers inside of the green box that represent 48 and $96 \mathrm{~h}$ after diagnosis of typhoid disease. NoTD, volunteers who did not develop typhoid disease; TD, volunteers who developed typhoid disease.

Comparisons between the levels of activated MAIT cells (single $\mathrm{CD}^{2} 8^{+}$or $\mathrm{CD} 38^{+} \mathrm{HLA}-\mathrm{DR}^{+}$) and the levels of total MAIT cells $\left(\mathrm{CD}^{+} \mathrm{CD}^{-} \mathrm{CD} 8^{+} \mathrm{CD} 161^{\text {high }} \mathrm{TCR} \mathrm{V} \alpha 7.2^{+}\right)$were performed using Pearson product-moment correlation. We found an inverse correlation between MAIT cell activation and MAIT cell decline $\left(R^{2}=0.1207 ; P=0.0004\right.$ and $R^{2}=0.1679 ; P=0.0002$ for levels of total MAIT cells vs. either single CD $38^{+}$or double $\mathrm{CD}_{3}{ }^{+} \mathrm{HLA}-\mathrm{DR}^{+}$, respectively) (Figure S5 in Supplementary Material). Thus, high levels of either $\mathrm{CD}^{2} 8^{+}$single positive or CD $38^{+}{ }^{H L A}-D^{+}$double positive-activated MAIT cells are associated with a decline of MAIT cells in circulation.

\section{MAIT Cell Exhaustion and Apoptosis following Challenge with Wild-type S. Typhi}

To provide additional insights into the decline of MAIT cells in circulation, we measured the expression of CD57, a molecule whose expression is associated with cell exhaustion (25), and caspase-3, a molecule indicative of apoptosis (26). Similar to the expression of CD38 and HLA-DR markers and regardless of the dose, we found high levels of MAIT cells expressing CD57 and caspase-3 markers in TD volunteers after typhoid fever diagnosis (Figures 3A,C; Figures S6-S9 in Supplementary Material). No significant differences were found in the levels of MAIT cells expressing either CD57 or caspase- 3 between the high-dose and low-dose groups (Figure S10 in Supplementary Material). We also observed that the majority of the CD57 and caspase-3-expressing MAIT cells from TD participants were activated (Figures 3B,D; Figures S8 and S9 in Supplementary Material), and there was a direct correlation between the coexpression of CD38 ${ }^{+} \mathrm{HLA}-\mathrm{DR}^{+}$ and $\mathrm{CD}^{+} 7^{+}\left(R^{2}=0.1886 ; P=<0.0001\right)$ and caspase- $3^{+}$ $\left(R^{2}=0.1919 ; P<0.0001\right)$ surface markers (Figure $\mathrm{S} 11$ in Supplementary Material). No substantial increases in CD57 or caspase- 3 markers were observed in NoTD volunteers. These findings are consistent with a previously proposed model (27) in which MAIT cells are activated, exhausted, and depleted during the early stages of infection.

\section{MAIT Cell Proliferation Patterns following Challenge with S. Typhi}

Because a well-described consequence of immune activation is cell proliferation, we hypothesized that MAIT cells from TD volunteers might have been more susceptible to activation-induced proliferation than MAIT cells from NoTD volunteers. To test this hypothesis, we examined the levels of Ki67 proliferationassociated antigen on MAIT cells. We found that regardless of the dose, $\mathrm{Ki} 67^{+}$MAIT cells expanded after the challenge in TD volunteers, with sharp increases observed at 48 and $96 \mathrm{~h}$ after diagnosis of TD (Figures 4A-E; Figures S12A and S13A in Supplementary Material). Interestingly, while during the development of typhoid fever, the proliferation of CD38-positive MAIT cells was significantly higher in low-dose TD volunteers than in high-dose TD volunteers (Figures 4F, G; Figure S14B in Supplementary Material); no differences between the coexpression of Ki67 and either caspase or $\mathrm{CD} 57^{+}$were found between the high- and low-dose groups (Figures 5A,B; Figures S12B, S13B, and S14B in Supplementary Material).

\section{MAIT Cell Homing Patterns following Challenge with S. Typhi}

An explanation for the lower numbers of activation-dependent MAIT cell proliferation detected in the blood of high-dose TD volunteers as compared with low-dose TD volunteers is that the MAIT cells from the former volunteers home earlier and/or at higher levels to other compartments in the host (e.g., gut and inflamed tissues). To address this possibility, we measured the expression of CCR9 and CCR6 molecules, which are involved in the homing of cells to the gut and inflamed tissues, respectively. We found that, during typhoid fever, although the frequencies of CD38+-activated MAIT cells expressing CCR6 or CCR9 homing markers were increased in all TD volunteers (regardless of the dose), their expression levels in the high-dose group were significantly lower than those observed in TD volunteers from the low-dose group (Figures 6A,B; Figures S6, S7, and S15-S17 in Supplementary Material). Moreover, the magnitude of MAIT cells coexpressing CCR6 and CCR9 markers were significantly higher, during typhoid fever, in TD volunteers receiving the low-dose inoculum than in TD volunteers receiving the high-dose inoculum (Figure 6C; Figures S6, S7, and S15-S17 in Supplementary Material). We also noted that the frequencies of CD38-positive MAIT cells expressing either CCR6 or CCR9 homing molecules remain unchanged in NoTD from both high- and low-dose groups (Figures 6A,B). Thus, the exposure to higher numbers of organisms might affect the homing of MAIT cells to inflamed tissues. To evaluate this possibility, we measured the presence of MAIT cells coexpressing caspase-3 and either CCR6 or CCR9 markers. We found that, although MAIT cells coexpressing caspase-3 and either CCR6 or CCR9 markers were significantly higher in TD (during typhoid fever) than in NoTD (7-9 days after challenge) volunteers, no significant differences were observed when comparing low- and high-dose TD volunteers at 48-96 h (Figures 6D,E; Figure S18 in Supplementary Material). The differences between TD and NoTD volunteers might be due 


\section{Gated on Ki67+ MAIT cells}

\section{Low-Dose}

A

NoTD

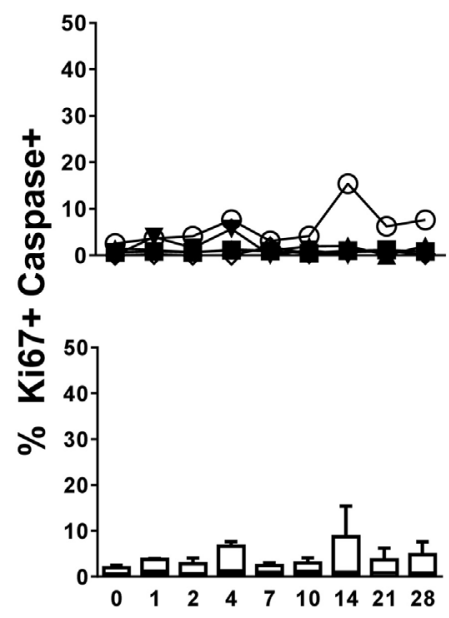

B

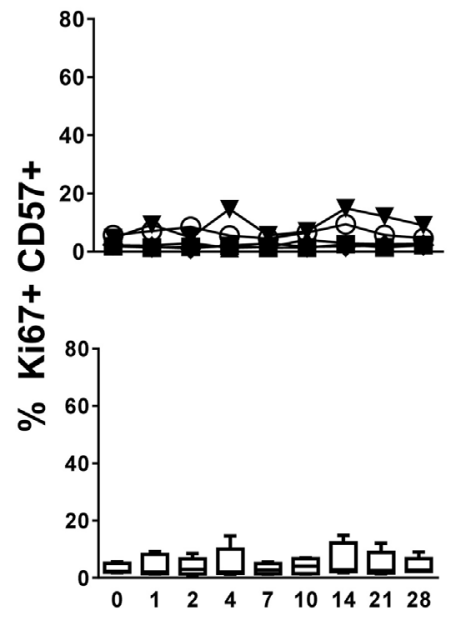

TD
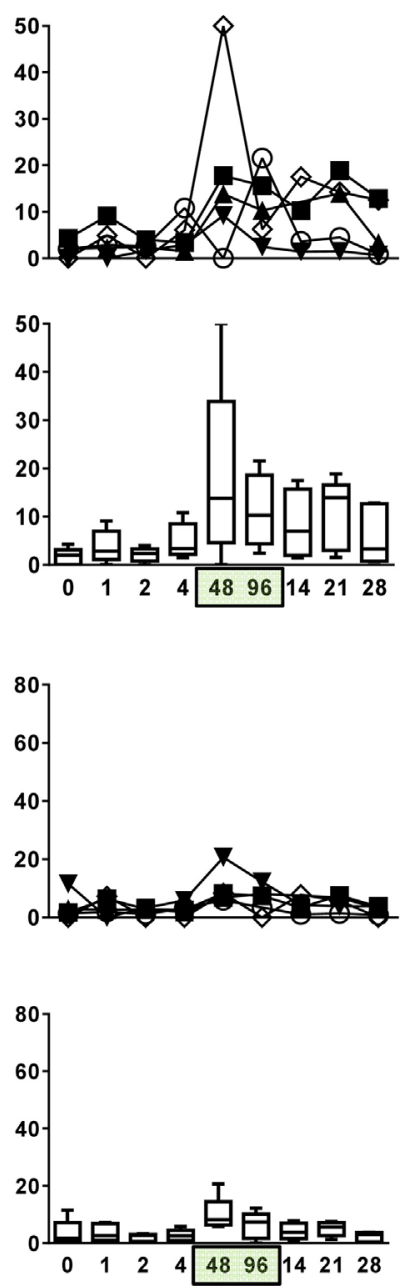

High-Dose

NoTD
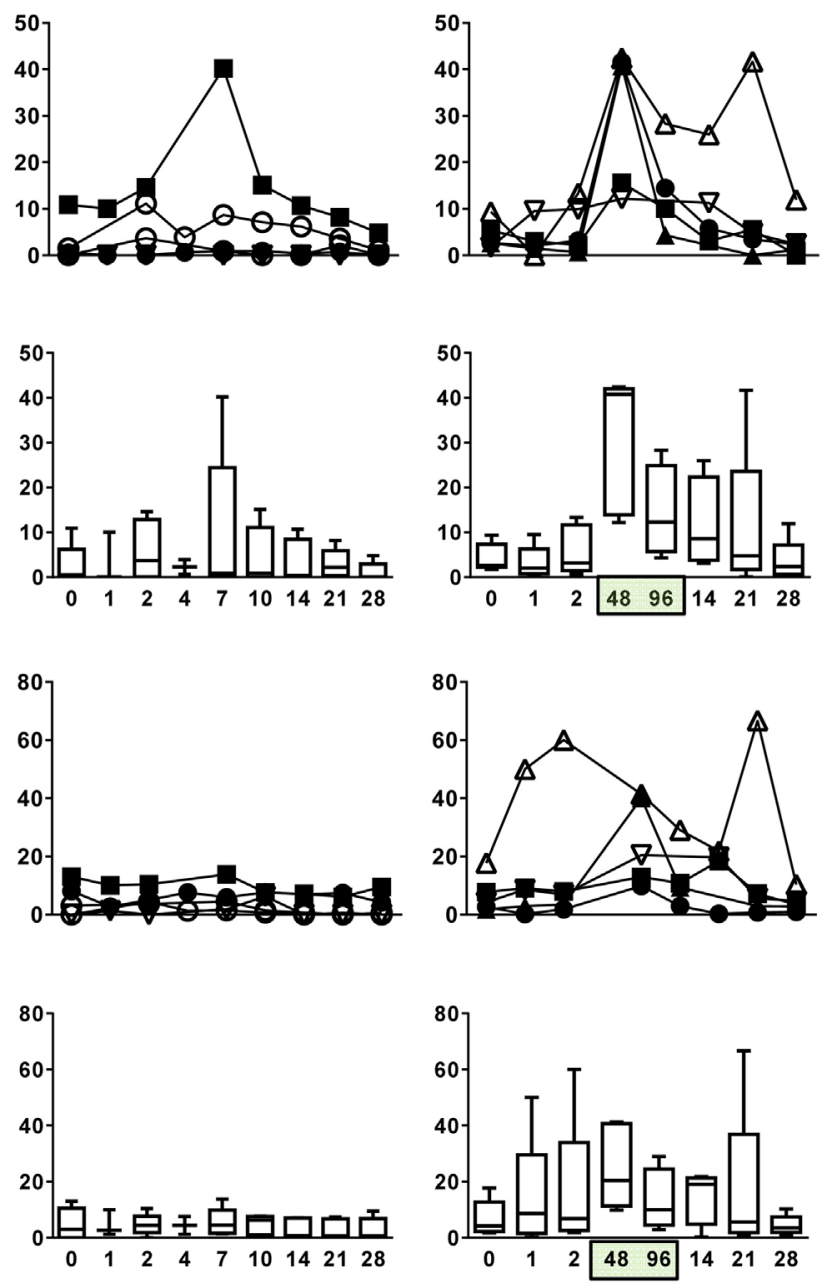

\section{Days after challenge}

FIGURE 5 | Evaluation of exhaustion and apoptosis in proliferating MAIT cells. Ex vivo peripheral blood mononuclear cells were analyzed as described in Figure 1. Expression of CD57 and caspase-3 were performed to identify exhausted and apoptotic in proliferating MAIT cells, respectively. Individual and combined data of Ki67 $7^{+}$MAIT cells expressing (A) capsase-3 or (B) CD57 surface markers are shown. MAIT cells were sequentially gated on Ki67 ${ }^{+}$and then on capsase-3 or CD57 surface markers. Bar graphs extend from the 25th to 75th percentiles, and the line in the middle represents the median of the pooled data from the five different subjects. The whiskers delineate the smallest to the largest value. Numbers in the " $X$ " axis represent days after the challenge, except for the numbers inside of the green box that represent 48 and $96 \mathrm{~h}$ after diagnosis of typhoid disease. NoTD, volunteers who did not develop typhoid disease; TD, volunteers who developed typhoid disease.

to a disproportionate number of activation-induced proliferating MAIT cells undergoing caspase-3-mediated death during typhoid fever. On the other hand, the differences between TD volunteers receiving high and low doses might result from the numbers of MAIT cells recorded in circulation, which are homing to the inflamed gut, as measured by the expression of gut homing molecules.

\section{DISCUSSION}

Despite the predicted importance of MAIT cell responses in protection against bacterial infection, very limited data are available concerning the time kinetics and characterization of these responses following bacterial infection in humans. Here, we described for the first time the kinetics of MAIT cells up to 


\section{Gated on MAIT cells}

\section{Low-Dose}

A

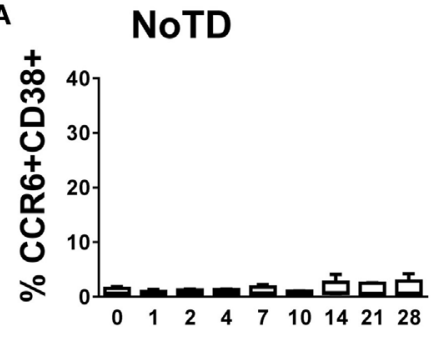

B

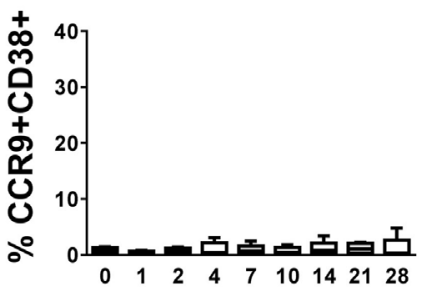

C

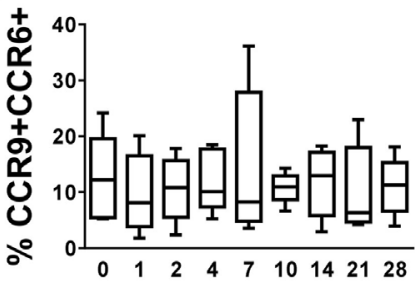

D
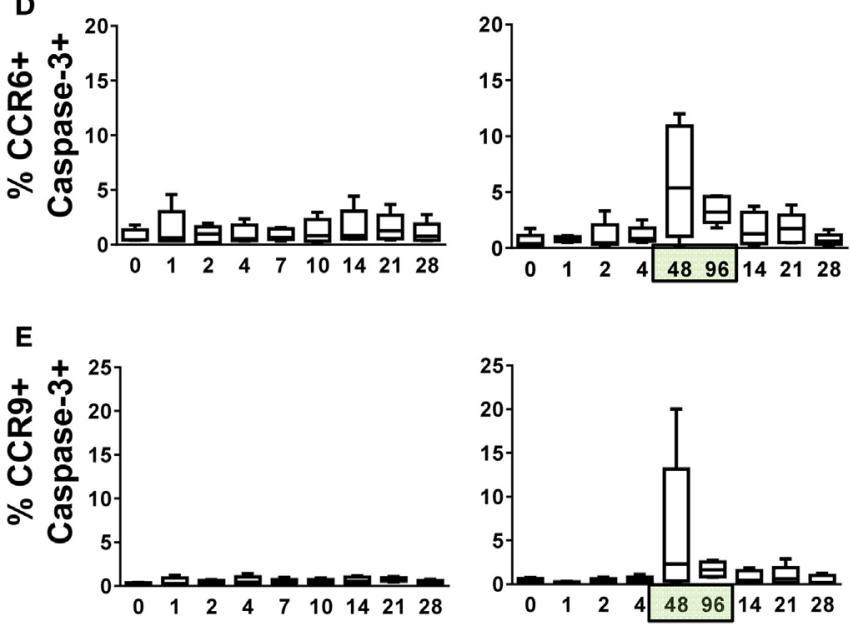

TD

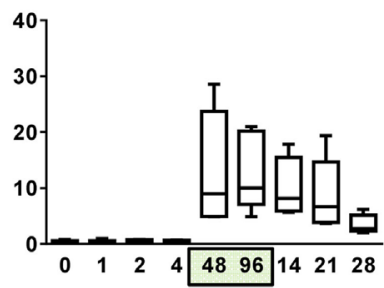

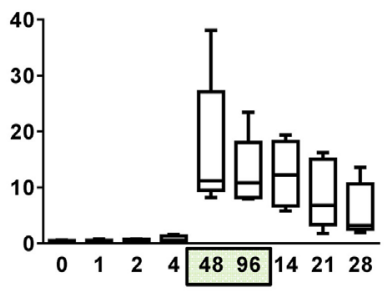
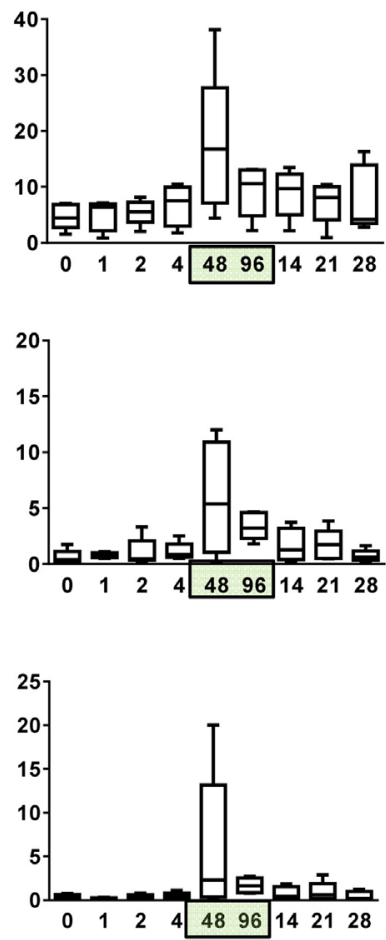

\section{High-Dose}

NoTD
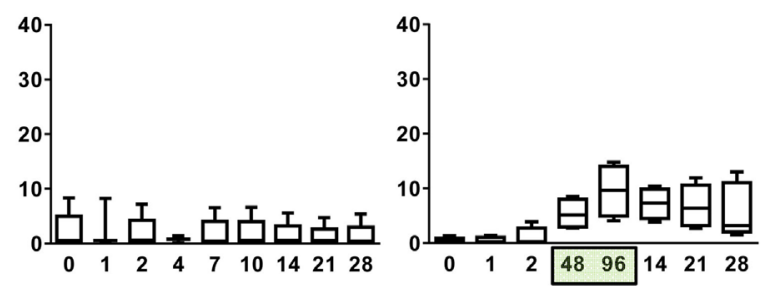
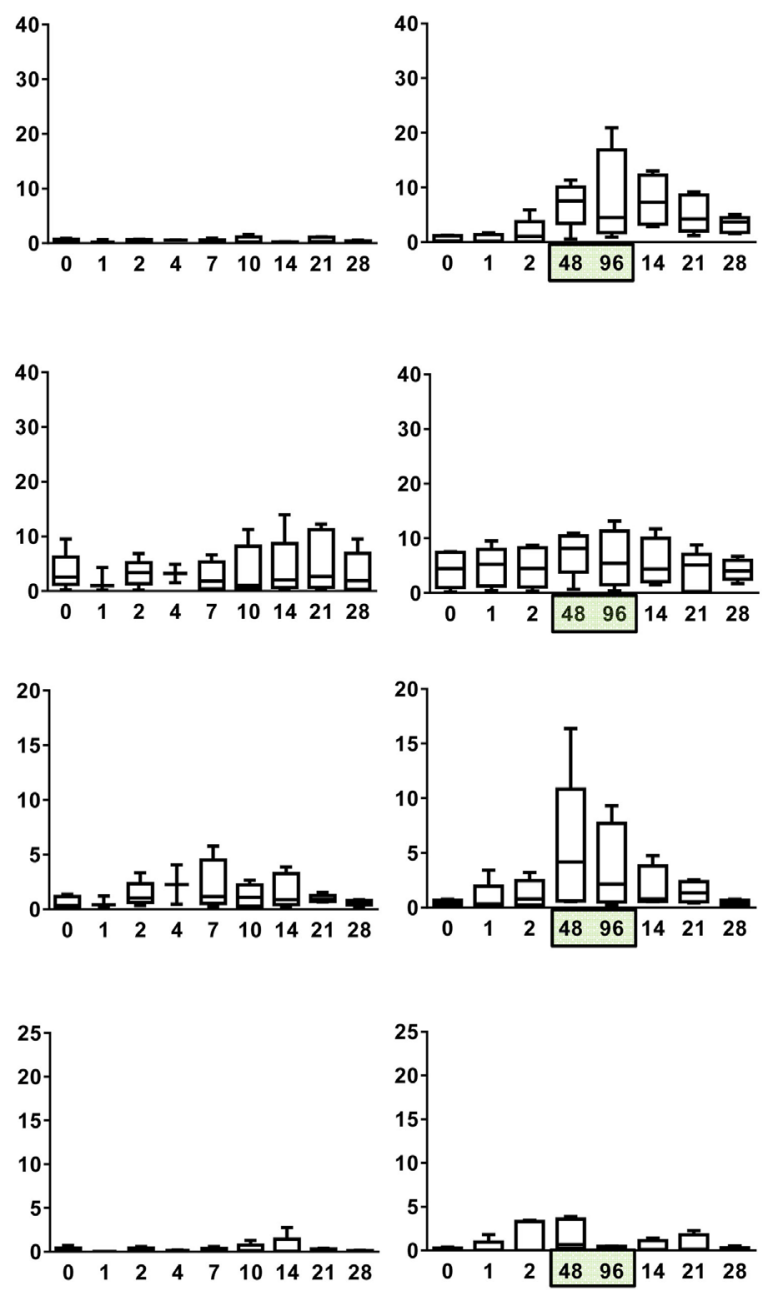

\section{Days after challenge}

FIGURE 6 | Evaluation of the homing potential of MAIT cells following Salmonella enterica serovar Typhi challenge. Ex vivo peripheral blood mononuclear cells were analyzed as described in Figure 1. Additional gating on CCR6 and CCR9 were performed to identify MAIT cells with the potential to home to inflamed and gut tissues, respectively. Combined data of MAIT cells coexpressing (A) CCR6 and CD38, (B) CCR9 and CD38, (C) CCR6 and CCR9, (D) CCR6 and caspase-3, and (E) CCR9 and caspase-3 surface markers. Bar graphs extend from the 25th to 75th percentiles, and the line in the middle represents the median of the pooled data from the five different subjects. The whiskers delineate the smallest to the largest value. Numbers in the "X" axis represent days after the challenge, except for the numbers inside of the green box that represent 48 and $96 \mathrm{~h}$ after diagnosis of typhoid disease. NoTD, volunteers who did not develop typhoid disease; TD, volunteers who developed typhoid disease. 
28 days following oral challenge of volunteers with wild-type S. Typhi. We observed that MAIT cells, possibly because of increased exposure in vivo to the microbes or their components, are activated, exhausted, and depleted during the infection.

MAIT cells are an important physiological component of the bacterial host defense and may also be involved in inflammatory disorders $(7,28,29)$. In fact, previous studies have demonstrated that MAIT cells may play a significant role in Vibrio cholerae (30), Mycobacterium tuberculosis (TB) (31), and human immunodeficiency virus (HIV) $(27,32)$ infections in humans. For example, Gold and colleagues have shown that in humans, MAIT cells are decreased in the blood of patients with active TB infection (31). In other studies, levels of MAIT cells were found to be severely reduced in the circulation of patients with $\operatorname{HIV}-1$ infection $(27,32)$, and their decline was associated with the time of diagnosis (27). Thus, we hypothesized that upon microbial stimulation by $S$. Typhi, functionally active circulating MAIT cells expressing gut migratory patterns might play a role in the S. Typhi infection.

In this manuscript, we reported that the levels of proliferating MAIT cells from TD volunteers were higher than in NoTD volunteers. These differences were not caused by altered levels of T-cell subsets at baseline (day 0), since baseline levels of $\mathrm{CD}^{+}$, $\mathrm{CD}^{+}$, and MAIT cell populations were similar among TD and NoTD volunteers (Figure S19 in Supplementary Material). A key property of protective immunity is the ability of conventional $\mathrm{CD}^{+} \mathrm{T}$ cells to undergo rapid proliferation, so that a large pool of memory cells is available to fight the infection (33). After birth, MAIT cells acquire a memory phenotype and expand dramatically in the mucosa and periphery (6). Thus, similar to conventional $\mathrm{CD}^{+} \mathrm{T}$ cells, MAIT cell expansion is likely to be the result of the antigen presentation. Thus, one would expect that increased bacterial loads would lead to greater MAIT cell proliferation. However, during typhoid fever, we found higher levels of activated $\left(\mathrm{CD} 38^{+}\right)$proliferating MAIT cells in TD volunteers receiving a low dose than in those TD volunteers receiving a high dose of the inoculum. Thus, it is reasonable to speculate that this phenomenon might be the result of factors such as the initial amount of the inoculum and its ability to activate MAIT cell responses. This assumption is based on previous work from our group and others showing that the quality of MAIT cell responses is dependent on bacterial load (12), and that the accumulation of MAIT cells in the mucosa is dependent on the size of the bacterial inoculum (34). Previous observations showing that partial or incomplete antigenic activation can induce defects in proliferation (35) also support this theory. Moreover, previous reports had shown that MAIT cells are more susceptible to activation-driven apoptosis than conventional T cells (36), and that antigen-driven $\mathrm{CD}^{+} \mathrm{T}$ cell proliferation is lower in volunteers exhibiting high viral load $(37,38)$. However, it is not possible to exclude the possibility that the differential proliferation might be due to an increased level of MAIT cells undergoing apoptosis after being infected by $S$. Typhi. In fact, previous studies from our group have shown that $S$. Typhi readily infects T cells (39) and that heavily $S$. Typhi-infected cells can undergo apoptosis-mediated cell death $(40,41)$.

Our results also suggest that MAIT cells from TD volunteers acquire different homing patterns in function of the initial bacterial dose. As previously demonstrated in cells isolated from blood $(7,32)$ and colon (42), most MAIT cells express the chemokine receptors CCR6 and CCR9, presumably contributing to their intestinal localization. Here, we report that activated $\left(\mathrm{CD} 38^{+}\right)$MAIT cells coexpressing CCR6 and CCR9 markers were significantly higher during typhoid fever in TD volunteers receiving the low-dose inoculum than in TD volunteers receiving the high-dose inoculum. Thus, increases of CCR6 and CCR9-positive MAIT cells coexpressing CD38 observed in circulation might translate to a lower recruitment of MAIT cells to the inflamed intestinal mucosa in volunteers receiving the high-dose inoculum. This hypothesis is consistent with recent work showing that MAIT cell numbers are lower in the intestinal mucosa of patients with inflammatory bowel disease than in healthy controls (43). However, little is known about the initial steps triggering MAIT cell homing to the inflamed tissues. Thus, studies aiming to examine the interactions between MAIT cells and antigen-presenting cells are needed to define further and characterize the effects of the inoculum size on MAIT cell homing behavior.

It is important to note that the investigators are acutely aware that the relatively small number of volunteers available for the studies presented in this manuscript, largely resulting from the limitations inherent in the performance of challenges with wildtype organisms in humans, is an overall weakness. However, this weakness will mainly affect the study if the null hypothesis is not rejected. Indeed, the relatively small number of volunteers studied did not preclude us from observing strong, statistically significant differences between volunteers allocated to the different cohorts. Upcoming studies with larger numbers of volunteers are required to confirm and expand the findings detailed in this manuscript.

In sum, to the best of our knowledge, this is the first body of work to show in humans the kinetics and characteristics of circulating MAIT cells after $S$. Typhi infection. These observations are of particular importance in that they provide direct evidence in humans that the exposure to $S$. Typhi not only alters the levels of activation of MAIT cells but also influences their proliferation and homing patterns. These findings also argue that MAIT cells play an integral role in the immune response against Salmonella infection and might help to maintain a balance between healthy and disease in the gut microenvironment. Gastrointestinal infections by $S$. Typhi are rare in industrialized countries. However, it remains a major public health problem in the developing world. Control measures such as sanitation, food hygiene, and vaccination are high priorities.

\section{ETHICS STATEMENT}

All blood collection was approved by National Research Ethic Service (NRES), Oxfordshire Research Ethics Committee A (10/H0604/53). This protocol has been conducted in accordance with the ethical standards laid down in the 1964 Declaration of Helsinki and the principles of the International Conference on Harmonization Good Clinical Practice guidelines (14, 44). Volunteers were explained the purpose of this study and gave informed, signed consent before the blood draw. All blood specimens were processed within $4 \mathrm{~h}$ of the blood draw. PBMC were 
isolated from the blood by density gradient centrifugation and cryopreserved in liquid $\mathrm{N}_{2}$ following standard techniques (14).

\section{AUTHOR CONTRIBUTIONS}

RS-G designed the study, performed the experiments, analyzed the data, and wrote the manuscript; DL and SF performed the experiments, analyzed the data, and helped draft the manuscript; LM contributed to the design, performed statistical analyses, and helped draft the manuscript; TD, CJ, CW, CB, and BA contributed to the design, collected and processed the clinical samples, and helped draft the manuscript, ML developed the challenge model, contributed to the design, and helped draft the manuscript; AP and MS contributed to the design and analysis of the data and wrote the manuscript.

\section{ACKNOWLEDGMENTS}

We are indebted to the volunteers who allowed us to perform this study. We also thank Dr. Haiyan Chen Mrs. Regina Harley, and Catherine Storrer for excellent technical assistance. This work was

\section{REFERENCES}

1. Tilloy F, Treiner E, Park SH, Garcia C, Lemonnier F, de la Salle H, et al. An invariant $\mathrm{T}$ cell receptor alpha chain defines a novel TAP-independent major histocompatibility complex class Ib-restricted alpha/beta $\mathrm{T}$ cell subpopulation in mammals. J Exp Med (1999) 189:1907-21. doi:10.1084/ jem.189.12.1907

2. Treiner E, Duban L, Bahram S, Radosavljevic M, Wanner V, Tilloy F, et al. Selection of evolutionarily conserved mucosal-associated invariant T cells by MR1. Nature (2003) 422:164-9. doi:10.1038/nature01433

3. Le Bourhis L, Martin E, Peguillet I, Guihot A, Froux N, Core M, et al. Antimicrobial activity of mucosal-associated invariant T cells. Nat Immunol (2010) 11:701-8. doi:10.1038/ni.1890

4. Leeansyah E, Loh L, Nixon DF, Sandberg JK. Acquisition of innate-like microbial reactivity in mucosal tissues during human fetal MAIT-cell development. Nat Commun (2014) 5:3143. doi:10.1038/ncomms4143

5. Napier RJ, Adams EJ, Gold MC, Lewinsohn DM. The role of mucosal associated invariant T cells in antimicrobial immunity. Front Immunol (2015) 6:344 doi:10.3389/fimmu.2015.00344

6. Martin E, Treiner E, Duban L, Guerri L, Laude H, Toly C, et al. Stepwise development of MAIT cells in mouse and human. PLoS Biol (2009) 7:e54. doi:10.1371/journal.pbio.1000054

7. Dusseaux M, Martin E, Serriari N, Peguillet I, Premel V, Louis D, et al. Human MAIT cells are xenobiotic-resistant, tissue-targeted, CD161hi IL-17-secreting T cells. Blood (2011) 117:1250-9. doi:10.1182/blood-2010-08-303339

8. Savage AK, Constantinides MG, Han J, Picard D, Martin E, Li B, et al. The transcription factor PLZF directs the effector program of the NKT cell lineage. Immunity (2008) 29:391-403. doi:10.1016/j.immuni.2008.07.011

9. Sharma PK, Wong EB, Napier RJ, Bishai WR, Ndung'u T, Kasprowicz VO, et al. High expression of CD26 accurately identifies human bacteria-reactive MR1-restricted MAIT cells. Immunology (2015) 145:443-53. doi:10.1111/ imm. 12461

10. van Wilgenburg B, Scherwitzl I, Hutchinson EC, Leng T, Kurioka A, Kulicke $\mathrm{C}$, et al. MAIT cells are activated during human viral infections. Nat Commun (2016) 7:11653. doi:10.1038/ncomms11653

11. Le Bourhis L, Dusseaux M, Bohineust A, Bessoles S, Martin E, Premel V, et al. MAIT cells detect and efficiently lyse bacterially-infected epithelial cells. PLoS Pathog (2013) 9:e1003681. doi:10.1371/journal.ppat.1003681

12. Salerno-Goncalves R, Rezwan T, Sztein MB. B cells modulate mucosal associated invariant T cell immune responses. Front Immunol (2014) 4:511. doi:10.3389/fimmu.2013.00511 supported, in part, by NIAID, NIH, DHHS federal research grants R01 AI036525, U19 AI082655 [Cooperative Center for Human Immunology (CCHI)], and U19-AI109776 [Center of Excellence for Translational Research (CETR)] to MS and by a Strategic Translation Award from the Wellcome Trust (grant number 092661), the NIHR Oxford Biomedical Research Centre (Clinical Research Fellowships to CW and TD), the Jenner Institute, the Oxford Martin School, and the European Union (FP7, Marie Curie Research Fellowship to CB). SF was funded in part by NIH Fellowship Training Program in Vaccinology T32-AI07524. The content is solely the responsibility of the authors and does not necessarily represent the official views of the National Institute of Allergy and Infectious Diseases, the National Institutes of Health, the National Health Service, the National Institute for Health Research (NIHR), or the UK Department of Health.

\section{SUPPLEMENTARY MATERIAL}

The Supplementary Material for this article can be found online at http://journal.frontiersin.org/article/10.3389/fimmu.2017. 00398/full\#supplementary-material.

13. Hornick RB, Woodward WE, Greisman SE. Doctor T. E. Woodward's legacy: from typhus to typhoid fever. Clin Infect Dis (2007) 45(Suppl 1):S6-8. doi: $10.1086 / 518138$

14. Waddington CS, Darton TC, Jones C, Haworth K, Peters A, John T, et al. An outpatient, ambulant-design, controlled human infection model using escalating doses of Salmonella Typhi challenge delivered in sodium bicarbonate solution. Clin Infect Dis (2014) 58:1230-40. doi:10.1093/cid/ciu078

15. Sztein MB, Salerno-Goncalves R, McArthur MA. Complex adaptive immunity to enteric fevers in humans: lessons learned and the path forward. Front Immunol (2014) 5:516. doi:10.3389/fimmu.2014.00516

16. Booth JS, Salerno-Goncalves R, Blanchard TG, Patil SA, Kader HA, Safta $\mathrm{AM}$, et al. Mucosal-associated invariant T cells in the human gastric mucosa and blood: role in Helicobacter pylori infection. Front Immunol (2015) 6:466. doi:10.3389/fimmu.2015.00466

17. Darton TC, Blohmke CJ, Pollard AJ. Typhoid epidemiology, diagnostics and the human challenge model. Curr Opin Gastroenterol (2014) 30:7-17. doi:10.1097/MOG.0000000000000021

18. Salerno-Goncalves R, Wahid R, Sztein MB. Ex vivo kinetics of early and long-term multifunctional human leukocyte antigen E-specific CD8+ cells in volunteers immunized with the Ty21a typhoid vaccine. Clin Vaccine Immunol (2010) 17:1305-14. doi:10.1128/CVI.00234-10

19. McArthur MA, Sztein MB. Heterogeneity of multifunctional IL-17A producing S. Typhi-specific CD8+ T cells in volunteers following Ty21a typhoid immunization. PLoS One (2012) 7:e38408. doi:10.1371/journal.pone. 0038408

20. Fresnay S, McArthur MA, Magder L, Darton TC, Jones C, Waddington CS, et al. Salmonella Typhi-specific multifunctional CD8+ T cells play a dominant role in protection from typhoid fever in humans. J Transl Med (2016) 14:62. doi:10.1186/s12967-016-0819-7

21. Gao Y, Williams AP. Role of innate T cells in anti-bacterial immunity. Front Immunol (2015) 6:302. doi:10.3389/fimmu.2015.00302

22. Callan MF, Tan L, Annels N, Ogg GS, Wilson JD, O'Callaghan CA, et al. Direct visualization of antigen-specific CD8+ T cells during the primary immune response to Epstein-Barr virus in vivo. J Exp Med (1998) 187:1395-402. doi:10.1084/jem.187.9.1395

23. Miller JD, van der Most RG, Akondy RS, Glidewell JT, Albott S, Masopust $\mathrm{D}$, et al. Human effector and memory CD8+ T cell responses to smallpox and yellow fever vaccines. Immunity (2008) 28:710-22. doi:10.1016/j. immuni.2008.02.020

24. Santos-Oliveira JR, Regis EG, Leal CR, Cunha RV, Bozza PT, Da-Cruz AM. Evidence that lipopolysaccharide may contribute to the cytokine storm and 
cellular activation in patients with visceral leishmaniasis. PLoS Negl Trop Dis (2011) 5:e1198. doi:10.1371/journal.pntd.0001198

25. Brenchley JM, Karandikar NJ, Betts MR, Ambrozak DR, Hill BJ, Crotty LE, et al. Expression of CD57 defines replicative senescence and antigen-induced apoptotic death of CD8+ T cells. Blood (2003) 101:2711-20. doi:10.1182/ blood-2002-07-2103

26. Shi Y. Mechanisms of caspase activation and inhibition during apoptosis. Mol Cell (2002) 9:459-70. doi:10.1016/S1097-2765(02)00482-3

27. Leeansyah E, Ganesh A, Quigley MF, Sonnerborg A, Andersson J, Hunt PW, et al. Activation, exhaustion, and persistent decline of the antimicrobial MR1restricted MAIT-cell population in chronic HIV-1 infection. Blood (2013) 121:1124-35. doi:10.1182/blood-2012-07-445429

28. Le Bourhis L, Guerri L, Dusseaux M, Martin E, Soudais C, Lantz O. Mucosalassociated invariant $\mathrm{T}$ cells: unconventional development and function. Trends Immunol (2011) 32:212-8. doi:10.1016/j.it.2011.02.005

29. Wakao H, Yoshikiyo K, Koshimizu U, Furukawa T, Enomoto K, Matsunaga T, et al. Expansion of functional human mucosal-associated invariant $\mathrm{T}$ cells via reprogramming to pluripotency and redifferentiation. Cell Stem Cell (2013) 12:546-58. doi:10.1016/j.stem.2013.03.001

30. Leung DT, Bhuiyan TR, Nishat NS, Hoq MR, Aktar A, Rahman MA, et al. Circulating mucosal associated invariant $\mathrm{T}$ cells are activated in Vibrio cholerae $\mathrm{O} 1$ infection and associated with lipopolysaccharide antibody responses. PLoS Negl Trop Dis (2014) 8:e3076. doi:10.1371/journal.pntd. 0003076

31. Gold MC, Cerri S, Smyk-Pearson S, Cansler ME, Vogt TM, Delepine J, et al. Human mucosal associated invariant $\mathrm{T}$ cells detect bacterially infected cells. PLoS Biol (2010) 8:e1000407. doi:10.1371/journal.pbio.1000407

32. Cosgrove C, Ussher JE, Rauch A, Gartner K, Kurioka A, Huhn MH, et al. Early and nonreversible decrease of CD161++/MAIT cells in HIV infection. Blood (2013) 121:951-61. doi:10.1182/blood-2012-06-436436

33. Salerno-Goncalves R, Sztein MB. Cell-mediated immunity and the challenges for vaccine development. Trends Microbiol (2006) 14:536-42. doi:10.1016/j. tim.2006.10.004

34. Chen Z, Wang H, D'souza C, Sun S, Kostenko L, Eckle SB, et al. Mucosalassociated invariant $\mathrm{T}$-cell activation and accumulation after in vivo infection depends on microbial riboflavin synthesis and co-stimulatory signals. Mucosal Immunol (2017) 10:58-68. doi:10.1038/mi.2016.39

35. Schwartz RH. T cell anergy. Annu Rev Immunol (2003) 21:305-34. doi:10.1146/ annurev.immunol.21.120601.141110

36. Gerart S, Siberil S, Martin E, Lenoir C, Aguilar C, Picard C, et al. Human iNKT and MAIT cells exhibit a PLZF-dependent proapoptotic propensity that is counterbalanced by XIAP. Blood (2013) 121:614-23. doi:10.1182/ blood-2012-09-456095
37. Migueles SA, Laborico AC, Shupert WL, Sabbaghian MS, Rabin R, Hallahan $\mathrm{CW}$, et al. HIV-specific CD8+ T cell proliferation is coupled to perforin expression and is maintained in nonprogressors. Nat Immunol (2002) 3:1061-8. doi:10.1038/ni845

38. Wherry EJ, Blattman JN, Ahmed R. Low CD8 T-cell proliferative potential and high viral load limit the effectiveness of therapeutic vaccination. J Virol (2005) 79:8960-8. doi:10.1128/JVI.79.14.8960-8968.2005

39. Salerno-Goncalves R, Pasetti MF, Sztein MB. Characterization of CD8(+) effector $\mathrm{T}$ cell responses in volunteers immunized with Salmonella enterica serovar Typhi strain Ty21a typhoid vaccine. J Immunol (2002) 169:2196-203. doi:10.4049/jimmunol.169.4.2196

40. Grant AJ, Sheppard M, Deardon R, Brown SP, Foster G, Bryant CE, et al. Caspase-3-dependent phagocyte death during systemic Salmonella enterica serovar Typhimurium infection of mice. Immunology (2008) 125:28-37. doi:10.1111/j.1365-2567.2008.02814.x

41. Salerno-Goncalves R, Sztein MB. Priming of Salmonella enterica serovar Typhi-specific CD8(+) T cells by suicide dendritic cell cross-presentation in humans. PLoS One (2009) 4:e5879. doi:10.1371/journal.pone.0005879

42. Sundstrom P, Ahlmanner F, Akeus P, Sundquist M, Alsen S, Yrlid U, et al. Human mucosa-associated invariant $\mathrm{T}$ cells accumulate in colon adenocarcinomas but produce reduced amounts of IFN-gamma. J Immunol (2015) 195:3472-81. doi:10.4049/jimmunol.1500258

43. Hiejima E, Kawai T, Nakase H, Tsuruyama T, Morimoto T, Yasumi T, et al. Reduced numbers and proapoptotic features of mucosal-associated invariant $\mathrm{T}$ cells as a characteristic finding in patients with IBD. Inflamm Bowel Dis (2015) 21:1529-40. doi:10.1097/MIB.0000000000000397

44. International conference on harmonisation of technical requirements for registration of pharmaceuticals for human use (ICH) adopts consolidated guideline on good clinical practice in the conduct of clinical trials on medicinal products for human use. Int Dig Health Legis (1997) 48:231-4.

Conflict of Interest Statement: The authors declare that the research was conducted in the absence of any commercial or financial relationships that could be construed as a potential conflict of interest.

Copyright (c) 2017 Salerno-Goncalves, Luo, Fresnay, Magder, Darton, Jones, Waddington, Blohmke, Angus, Levine, Pollard and Sztein. This is an open-access article distributed under the terms of the Creative Commons Attribution License (CC BY). The use, distribution or reproduction in other forums is permitted, provided the original author(s) or licensor are credited and that the original publication in this journal is cited, in accordance with accepted academic practice. No use, distribution or reproduction is permitted which does not comply with these terms. 